OPEN ACCESS

Edited by:

Carina Mallard,

University of Gothenburg, Sweden

Reviewed by:

Angela Leigh Cumberland,

RMIT University, Australia

Sandra Buratta,

University of Perugia, Italy

${ }^{*}$ Correspondence:

Sigrun Lange

S.lange@westminster.ac.uk

Mariya Hristova

m.hristova@ucl.ac.uk

Specialty section:

This article was submitted to

Embryonic and Developmental

Physiology,

a section of the journal

Frontiers in Physiology

Received: 13 December 2018

Accepted: 04 March 2019

Published: 19 March 2019

Citation:

Sisa C, Kholia S, Naylor J, Herrera Sanchez MB, Bruno S, Deregibus MC, Camussi G, Inal JM,

Lange S and Hristova M (2019)

Mesenchymal Stromal Cell Derived

Extracellular Vesicles Reduce

Hypoxia-Ischaemia Induced Perinatal

Brain Injury. Front. Physiol. 10:282.

doi: 10.3389/fphys.2019.00282

\section{Mesenchymal Stromal Cell Derived Extracellular Vesicles Reduce Hypoxia-Ischaemia Induced Perinatal Brain Injury}

\author{
Claudia Sisa ${ }^{1}$, Sharad Kholia ${ }^{2}$, Jordan Naylor ${ }^{1}$, Maria Beatriz Herrera Sanchez, \\ Stefania Brunoㄹ, Maria Chiara Deregibus ${ }^{3}$, Giovanni Camussi' ${ }^{2}$, Jameel M. Inal ${ }^{4}$, \\ Sigrun Lange ${ }^{5 *}$ and Mariya Hristova ${ }^{1 *}$
}

' Perinatal Brain Protection and Repair Group, EGA Institute for Women's Health, University College London, London, United Kingdom, ${ }^{2}$ Department of Medical Sciences, University of Turin, Turin, Italy, ${ }^{3}$ 2i3T, Incubator and Technology Transfer, Molecular Biotechnology Center, University of Turin, Turin, Italy, ${ }^{4}$ Extracellular Vesicle Research Unit and Bioscience Research Group, School of Life and Medical Sciences, University of Hertfordshire, Hatfield, United Kingdom, ${ }^{5}$ Tissue Architecture and Regeneration Research Group, School of Life Sciences, University of Westminster, London, United Kingdom

Background: Neonatal hypoxic-ischemic $(\mathrm{HI})$ insult is a leading cause of disability and death in newborns, with therapeutic hypothermia being the only currently available clinical intervention. Thus there is a great need for adjunct and novel treatments for enhanced or alternative post-HI neuroprotection. Extracellular vesicles (EVs) derived from mesenchymal stromal/stem cells (MSCs) have recently been shown to exhibit regenerative effects in various injury models. Here we present findings showing neuroprotective effects of MSC-derived EVs in the Rice-Vannucci model of severe $\mathrm{HI}$-induced neonatal brain insult.

Methods: Mesenchymal stromal/stem cell-derived EVs were applied intranasally immediately post $\mathrm{HI}$-insult and behavioral outcomes were observed $48 \mathrm{~h}$ following MSC-EV treatment, as assessed by negative geotaxis. Brains were thereafter excised and assessed for changes in glial responses, cell death, and neuronal loss as markers of damage at $48 \mathrm{~h}$ post $\mathrm{HI}$-insult.

Results: Brains of the MSC-EV treated group showed a significant decrease in microglial activation, cell death, and percentage tissue volume loss in multiple brain regions, compared to the control-treated groups. Furthermore, negative geotaxis test showed improved behavioral outcomes at $48 \mathrm{~h}$ following MSC-EV treatment.

Conclusion: Our findings highlight the clinical potential of using MSC-derived EVs following neonatal hypoxia-ischaemia.

Keywords: hypoxia, ischaemia, extracellular vesicles, mesenchymal stromal/stem cells, microglia, neuroprotection 


\section{INTRODUCTION}

Neonatal hypoxic-ischaemic (HI) brain injury is a major contributing factor to cerebral palsy and other neurological disabilities and is estimated to occur in 3 in 1000 live births in the Western world and even at higher frequency in less developed countries (Perlman, 2006; Kurinczuk et al., 2010). Oxygen deprivation has been identified as a major cause of brain injury both in term and preterm babies (Wu and Colford, 2000; Hagberg et al., 2002; Mallard et al., 2003). While 15-20\% of affected neonates will die postnatally, it has been found that in surviving babies $5-10 \%$ will develop persistent motor deficiencies. Furthermore, $20-50 \%$ will suffer from sensory or cognitive abnormalities; for example approximately $15 \%$ of cerebral palsy cases are due to severe neonatal HI (Hack et al., 1992; Vohr et al., 2000; Volpe, 2012; Lee et al., 2013).

Following $\mathrm{HI}$ insult, changes in cellular transcription, mitochondrial function, de novo protein synthesis and posttranslational modifications all play pivotal roles (Culman et al., 2007; Pirianov et al., 2007; Yi et al., 2007). In experimental murine models of $\mathrm{HI}$, implications have for example been shown for epigenetic mechanisms (Kumral et al., 2012; Lange et al., 2014), pH changes (Kendall et al., 2011b; Uria-Avellanal and Robertson, 2014), cytokines (Kendall et al., 2011a), transcription factors (Hristova et al., 2016), and protein kinases (Thei et al., 2018). Reperfusion injury and associated reactive oxygen species, together with persistent inflammation, are also a significant contributor to brain damage in neonates following HI insult (Rocha-Ferreira and Hristova, 2016). Following positive outcomes in clinical studies of hypothermia (Wyatt et al., 2007), cooling brain or whole body to $33^{\circ} \mathrm{C}$ (moderate hypothermia) is currently the only strategy with a demonstrated clinical benefit. In full-term infants with moderate to severe $\mathrm{HI}$, cooling significantly improves survival and disability by $11 \%$ (Shankaran et al., 2012; Jacobs et al., 2013; Azzopardi et al., 2014). Importantly, as cooling is not always effective, with $40 \%$ of treated infants still suffering neurodevelopmental disabilities, recent studies have underscored the importance of combining hypothermia with safe adjunct therapies for more substantial neuroprotection. In addition, as hypothermia equipment is not readily available worldwide, novel safe and easy to apply treatments are of pivotal importance.

Mesenchymal stromal/stem cells (MSCs) have gained popularity over the years for their potential to implement regenerative medical treatment to damaged tissues of the body (Uccelli et al., 2008; Bruno et al., 2009; Gatti et al., 2011; Bruno et al., 2012; Lee et al., 2012; Tan et al., 2014; Collino et al., 2015; Heldring et al., 2015). Stem cells participate in the maintenance of homeostasis and restoration of tissues after injury through secretion of soluble factors and extracellular vesicles (EVs). EVs (exosomes and microvesicles) are 30$1000 \mathrm{~nm}$ lipid bilayer-enclosed structures which are released from parental cells and participate in cell-to-cell signaling processes. EVs have been shown to transport various biologically active molecules such as proteins, mRNAs, miRNAs, lncrRNAs, DNA, and lipids to target cells (Inal et al., 2012; Yeo et al., 2013; György et al., 2015; Bruno et al., 2017; Tricarico et al., 2017; van Niel et al., 2018). These molecules can act on various cell types by signaling proliferative and/or regenerative pathways including angiogenesis, cell proliferation, and immune tolerance (Deregibus et al., 2007; Camussi et al., 2010; Ranghino et al., 2012; de Jong et al., 2014; Robbins and Morelli, 2014; Lamichhane et al., 2015; Kholia et al., 2016; Merino-González et al., 2016; Zhang et al., 2016). Anti-inflammatory factors are one key group of molecules released by MSCs that are important in mediating repair and include interleukin 1 receptor agonist (IL-1ra) (Prockop and Oh, 2012), interleukin 10 (IL-10) (Németh et al., 2009), TNF- $\alpha$-stimulated gene-6 (TSG6) (Drago et al., 2013; English, 2013; Madrigal et al., 2014), prostaglandin (PG) E2 (Prockop and Oh, 2012; Drago et al., 2013; English, 2013; Németh et al., 2009), and indoleamine 2,3-dioxygenase (IDO) (Meisel et al., 2004; Croitoru-Lamoury et al., 2011; Kang et al., 2012; Lin et al., 2012; Rong et al., 2012).

Recent studies have suggested that EVs released from MSCs may be more important than the actual stem cells themselves in mediating tissue-protective effects due to the therapeutic factors secreted by EVs, including anti-inflammatory mediators, cytokines and growth factors, as well as microRNAs (Collino et al., 2015; Vallabhaneni et al., 2015; Bruno et al., 2017).

Studies in regenerative models, using total EVs or separate applications of either 100K EVs (population enriched with exosomes) or 10K EVs (population enriched with microvesicles), have led to indicate that $100 \mathrm{~K}$ EVs provide the bulk of proregenerative effects, although when total EVs were used it was found that $10 \mathrm{~K}$ EVs do not interfere negatively with $100 \mathrm{~K}$ EVs function (Bruno et al., 2017). Other studies have found that the application of total EVs was more effective than using isolated vesicle populations of $100 \mathrm{~K}$ EVs or $10 \mathrm{~K}$ EVs, respectively (Wen et al., 2016). Variations in these findings have not been fully explained yet but may possibly be due to differing target tissues.

HI studies using MSCs as putative treatment, have found that these stem cells have neuroprotective potential (van Velthoven et al., 2010; Kim et al., 2012; Donega et al., 2014; Park et al., 2015; Ahn et al., 2016; Corcelli et al., 2018) and the therapeutic time window was shown to be further extended when combining MSC treatment with hypothermia (Ahn et al., 2018). Furthermore, a potential for using stem cell derived EVs was recently shown in an ovine HI study, using intravenous administration of MSCderived EVs following transient umbilical cord occlusion in utero, which lead to improved brain function following MSC-EV treatment (Ophelders et al., 2016).

As intranasal administration has shown to be more efficient compared to intravenous administration in experimental $\mathrm{HI}$ models, due to direct transport to the CNS and bypassing peripheral elimination (Merkus and van den Berg, 2007; Hanson and Frey, 2008), we thus aimed in the present study at assessing whether intranasal administration of MSC-EVs following HI-insult would have neuroprotective effects. We used the Rice-Vannucci neonatal mouse model, which involves permanent unilateral common carotid artery occlusion followed by severe (1 h) hypoxia (Vannucci and Vannucci, 1997).

Here we provide evidence that compared to control-treated littermates, the brains of animals treated intranasally with MSC-derived EVs, immediately following $\mathrm{HI}$ insult, show 
significant neuroprotection and reduced neuroinflammation, as well as improved behavioral outcome, when assessed at $48 \mathrm{~h}$ post-treatment.

\section{MATERIALS AND METHODS}

\section{Animals and Procedures}

All animal experiments and care protocols were approved by the UK Home Office (PPL 70/8784) and UCL Animal Welfare and Ethical Review Board, carried out according to the United Kingdom Animals (Scientific Procedures) Act 1986. The ARRIVE guidelines were followed. Operations were performed at post-natal day 9 (P9) on C57/BI6 mice (Charles River, United Kingdom), bred in house, using a modification of the Rice-Vannucci model of neonatal HI as previously described (Hristova et al., 2010; Lange et al., 2014; Rocha-Ferreira et al., 2018). The parental animals were bred in an environment providing $12 \mathrm{~h}$ light/dark cycle and food and water ad libitum. The HI procedure was carried out as follows: P9 mice (males and females) were anesthetized using isoflurane (5\% induction, 1.5\% maintenance). Permanent occlusion of the left common carotid artery was established with $8 / 0$ polypropylene sutures followed by wound closure with tissue glue. The pups were recovered at $36^{\circ} \mathrm{C}$ and then were returned to the dam for $2 \mathrm{~h}$, whereafter they were placed in a $36^{\circ} \mathrm{C}$ hypoxic chamber for $60 \mathrm{~min}$, in humidified $10 \%$ oxygen $/ 90 \%$ nitrogen at $3 \mathrm{~L} / \mathrm{min}$. Immediately following hypoxic exposure, the animals were randomly allocated to HI, EV- or PBS-treatment group. The experimental (EV) group $(n=15)$ received one intranasal dose of $6 \mu \mathrm{L}$ of EVs (100KTOT-EV; $1.25 \times 10^{\wedge} 9$ particles/dose) in PBS, obtained from human bone marrow derived MSCs (Poietics hMSC, Cat no: PT-2501, Lot no: 0000446319, Lonza, Switzerland) and prepared according to Bruno et al. (2017). In brief, total EVs were isolated from characterized MSC cultures (Bruno et al., 2009), which were positive for the typical MSC markers (CD105, CD29, CD73, CD44, and CD90). The total EVs were collected from the supernatants of MSCs, cultured in fetal calf serum (FCS)-depleted RPMI medium, overnight. The EVs were a pool of $5 \mathrm{EV}$ isolations with each isolation comprised of 10 flasks with a passage number ranging from $\mathrm{P} 3$ to $\mathrm{P} 5$ progressively. Cell debris and apoptotic bodies were removed by centrifugation at $3000 \mathrm{~g}$ for $20 \mathrm{~min}$ and thereafter total EVs were isolated by ultracentrifugation for $2 \mathrm{~h}$ at $100,000 \mathrm{~g}$ at $4^{\circ} \mathrm{C}$ and stored at $-80^{\circ} \mathrm{C}$ until used. Details on EV characterization by nanoparticle tracking analysis (NTA, Nanosight, Malvern, United Kingdom), electron microscopy, FACS analysis and Western blotting for MSC-EV specific markers are shown in Supplementary Figure S1. EV payload characterization of proteomic and genomic content of these EVs was previously published in Bruno et al. (2017). The control treated groups received either $6 \mu \mathrm{L}$ intranasal phosphate-buffered saline (PBS) ( $n=14$; vehicle only group) or no intervention ( $n=16$; HI only group). The pups where returned to the dam and left for $48 \mathrm{~h}$ before behavioral assessment and subsequent histological analysis of extracted brains. All animals (both males and females) from all litters were used in the experiments. Following the $\mathrm{HI}$ protocol the mums and pups were observed and scored for welfare of neonatal rodents (Lloyd et al., 2000). All pups were taken care of by the mums and achieved overall scores $0-1$.

Post-natal day 9 mice were used in this particular experiment as they most closely resemble term neonates (Mallard and Vexler, 2015) and also possess injury responses phenotypically similar to white and gray matter damage, such as tissue loss, microgliamediated immunity, cell-death-mediated apoptosis, astrogliosis, and neurobehavioral alterations (Vannucci and Vannucci, 1997). The hypoxic chamber conditions were $10 \%$ oxygen/ $90 \%$ nitrogen according to previously described protocols (Rocha-Ferreira et al., 2018). Differences between male and female mice were not taken into account and male and female pups were combined in the analysis, as testosterone levels in mice are similar in both genders at this age (P9-P11) (Clarkson and Herbison, 2016).

\section{Tissue Sample Preparation}

For histological assessment, animals were sacrificed 48 h post$\mathrm{HI}$ insult with an intraperitoneal injection of pentobarbitone and perfusion with $30 \mathrm{~mL}$ of $4 \%$ paraformaldehyde in PBS. Brains were extracted and fixed in $4 \%$ paraformaldehyde in PBS at $4^{\circ} \mathrm{C}$ for $1 \mathrm{~h}$, followed by cryoprotection in $30 \%$ sucrose dissolved in phosphate buffer (PB) for $24 \mathrm{~h}$. Thereafter brains were frozen on dry ice, sectioned by cryostat into sequential $40 \mu \mathrm{m}$ sections and stored at $-80^{\circ} \mathrm{C}$ until histological analysis.

\section{Histological Analysis}

Coronal brain sections were compared between animals receiving MSC-derived EVs and control-treated animals (PBS-vehicle or HI only), for microglial activation, cell death, and infarct size. Tissue sections were scored blindly by two independent observers.

\section{Microglial Activation Assessment}

Tissue staining was performed according to established protocols as previously described (Hristova et al., 2010; Lange et al., 2014; Rocha-Ferreira et al., 2018). In brief, cryosections were thawed and rehydrated in distilled water, spread onto glass slides coated with $0.5 \%$ gelatine under a dissecting microscope, dried for $10 \mathrm{~min}$, fixed in $4 \%$ formaldehyde in $100 \mathrm{mM} \mathrm{PB}$ for $5 \mathrm{~min}$, treated with acetone (50, 100, 50\%: 2 min each), $0.1 \%$ bovine serum albumin (PB/BSA) and washed twice in $\mathrm{PB}$. The sections were pre-incubated with $5 \%$ goat serum (Sigma, St. Louis, MO, United States) in PB for $30 \mathrm{~min}$ and incubated overnight at $4^{\circ} \mathrm{C}$ with an antibody against $\alpha \mathrm{M} \beta 2$ integrin (Serotec, Oxford, United Kingdom) 1/5000. The sections were then washed in $\mathrm{PB} / \mathrm{BSA}, \mathrm{PB}, \mathrm{PB}, \mathrm{PB} / \mathrm{BSA}$ (2 min each), incubated with biotin-labeled anti-rat IgG (Vector Laboratories, Inc., Burlingame, CA, United States) and visualized with AvidinBiotinylated peroxidase Complex (ABC, Vector Laboratories, Inc.) and diaminobenzidine/hydrogen peroxide (DAB) stain. Sections were processed through alcohol and xylene and mounted with DEPEX (Sigma). Per animal, five cryosections (400 $\mu \mathrm{m}$ apart) of each brain were stained. Semi-quantitative scores for microglial activation were obtained as follows: $0=$ no activation; 1 = focal activation; 2 = mild phagocytic activation affecting $<50 \%$ of the region, thus showing diffuse activation with 
occasional phagocytic macrophages; 3 = phagocytic activation affecting $>50 \%$ of the region, thus showing widespread activation with predominant phagocytic macrophages; $4=$ total phagocytic activation (Rocha-Ferreira et al., 2015, 2018; Hristova et al., 2016). Microglial activation was scored for the following brain regions: cortex, pyriform cortex, hippocampus, striatum, thalamus, and external capsule. These regions were selected based on known selective vulnerability as a result of increased metabolic rate (Martin et al., 1997; Barkovich et al., 1998; Johnston et al., 2001, 2002; Volpe, 2001; McQuillen et al., 2003; Castillo, 2007; Leisman et al., 2014; Schmidt-Kastner, 2015).

\section{TUNEL Staining}

For assessment of changes in cell death, brain tissue sections were stained at $400 \mu \mathrm{m}$ intervals for DNA fragmentation using terminal deoxynucleotidyl transferase dUTP nick end labeling (TUNEL) according to the manufacturer's instructions (Roche, United Kingdom). Cell death was quantified by averaging the numerical count of TUNEL-positive nuclei in three representative optical fields in each brain region, comparing EV-treated versus control-treated brains.

\section{Infarct Volume Measurement}

Infarct volume was measured by Nissl stain in five coronal sections at $400 \mu \mathrm{m}$ intervals from each forebrain, stained with cresyl violet (VWR, United Kingdom). The Optimas 6.5 imaging analysis software (Bothell, WA, United States) was used to calculate the surviving brain tissue in each brain region as percentage between experimental and control side to estimate reduction in infarct size following EV treatment compared to control groups, according to previously described methods (Kendall et al., 2006).

\section{Behavioral Assessment by Negative Geotaxis}

The negative geotaxis test, assessing the labyrinthine reflex which reflects the strength and co-ordination of neonatal mice, was used for behavioral analysis in EV treated and control-treated or nontreated groups at $48 \mathrm{~h}$ post insult, before sacrificing the animals for brain extraction and subsequent histological assessment. The order of testing of the animals within the litters was randomly assigned. The mice were placed in the center of a $45^{\circ}$ incline board with their heads facing downwards. The time for the animal to make a $180^{\circ}$ turn to face upward and begin to move up the hill was recorded. Time was capped at $30 \mathrm{~s}$. If the animal failed to complete the task by this time, $30 \mathrm{~s}$ was the recorded outcome. Each animal attempted this task three times and these values were averaged per animal (Rocha-Ferreira et al., 2018). The animal numbers tested per group were as follows: MSC-EV treated: $n=10$; PBS-control treated: $n=10$; and HI-untreated control: $n=13$.

\section{Statistical Analysis}

Statistical analysis was carried out with GraphPad Prism 7 (La Jolla, CA, United States), using brain region as the repeated measure for the following statistical analyses:
The same six forebrain regions (cortex, pyriform cortex, hippocampus, striatum, thalamus, external capsule) were used for each outcome and each assay. Only the TUNEL data-set passed the D'Agostino and Pearson normality test. Normalized data (only one data set: TUNEL-thalamus) were analyzed using the one-way ANOVA test and the Tukey's multiple comparisons test.

It is likely that with repeated measures such as these the observations from a single subject are correlated, therefore the first stage of the analysis included the observations from all the regions tested in a single mixed model with a random subject effect, to produce an estimate of the treatment effect and associated inference that accounts for the correlations in the data arising from the repeated measures. Further post hoc Tukey's multiple comparisons test was carried out to assess evidence for subregional differences, $p<0.05$. Other regional data sets, being non-normalized data, were analyzed using the Kruskal-Wallis test and the Dunn's multiple comparisons test. For each outcome, the overall effect from the mixed linear model is reported, followed by the results from the individual regional post hoc tests. All data is presented as means and standard error of the mean (SEM) for each group. Group sizes ( $n=15 \mathrm{EV}$, $n=14 \mathrm{PBS}, n=16 \mathrm{HI}$ ), were based on power calculations for test power $>0.80$ and significance $<0.05$. Statistical significance was determined for $p$-value $<0.05$.

Statistical significance in the negative geotaxis behavioral testing was assessed through Kruskal-Wallis with Dunn's multiple comparison test, as the data was non-normally distributed. Normal distribution was assessed using ShapiroWilk normality test. The data is presented as individual values and median \pm interquartile bars.

\section{RESULTS}

\section{Intranasal Application of MSC-Derived EVs Decreases Microglial Activation in $\mathrm{HI}$}

Microglial activation (AlphaM), as assessed through $\alpha \mathrm{M} \beta 2$ integrin immunoreactivity, was significantly reduced in the EV-treated, compared to control PBS-treated groups overall (Kruskal-Wallis test $p=0.0168$, Dunn's multiple comparison test $p=0.0175)$ with subregional differences in cortex $(p=0.0319)$, hippocampus $(p=0.0392)$, and striatum $(p=0.0376)$ (Figure 1). Only a trend toward reduction, but not reaching significance, was observed in the other brain regions (Figure 1). Combining all six regions, using the Kruskal-Wallis test, the mean AlphaM scores varied significantly between treatment groups $(p=0.0168)$ (Figure 1).

\section{Intranasal Application of MSC-Derived EVs Decreases HI-Mediated Cell Death}

Intranasal application of MSC-derived EVs significantly reduced TUNEL+ cell death in cortex and external capsule (Figure 2). Using the Kruskal-Wallis test, the mean ipsilateral TUNEL+ cell counts per representative area in the cortex varied significantly between treatment groups (EV: 12.86; PBS: 26.09; HI: 32.82; 

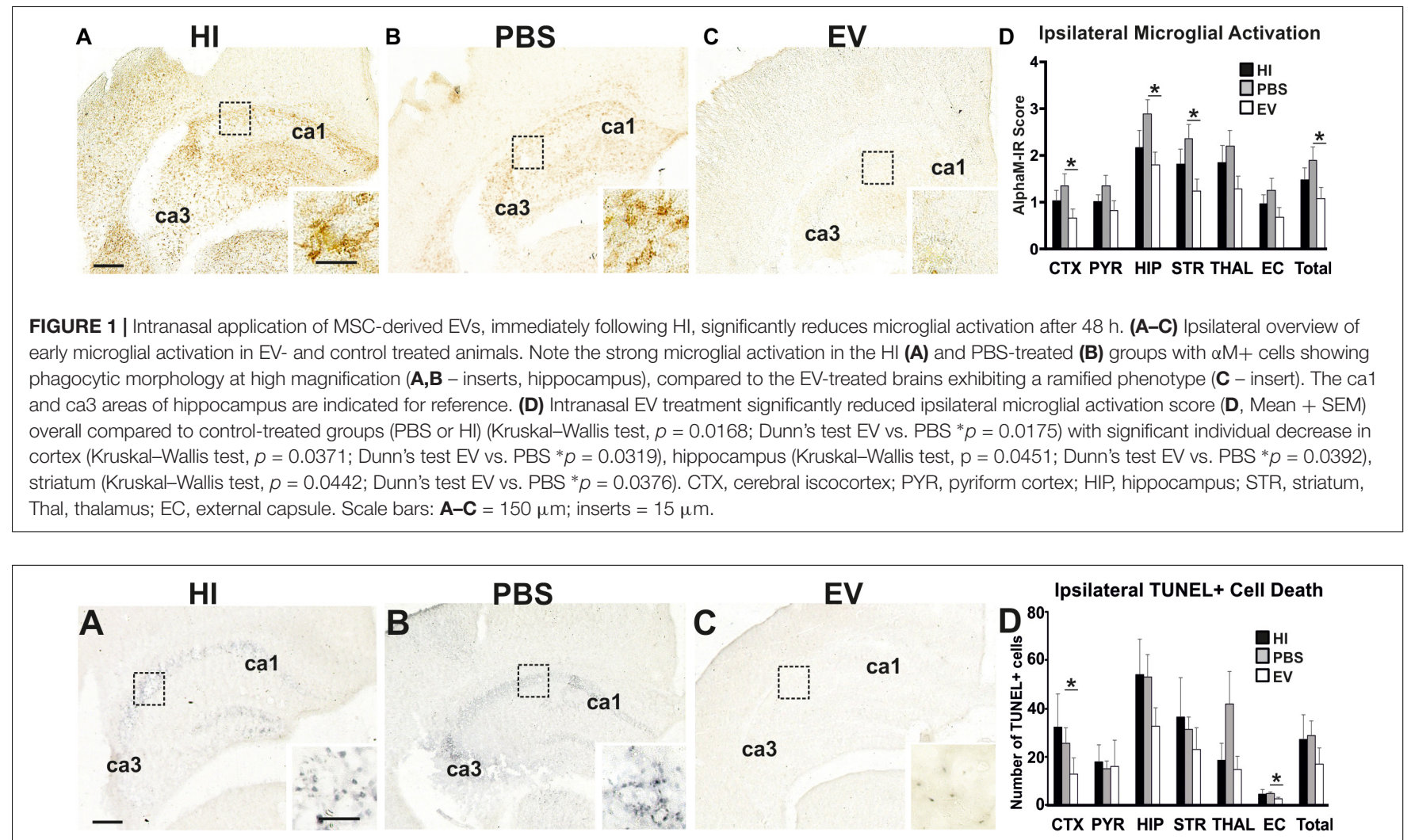

FIGURE 2 | Intranasal application of MSC-derived EVs, immediately following HI, significantly reduces TUNEL+ cell death after 48 h. (A-C) Histochemical overview of TUNEL+ cell death in the ipsilateral forebrain of HI (A), PBS- (B), and EV-treated (C) animals. Note the typical pyknotic nuclear morphology of the TUNEL+ cells observed in the $\mathrm{HI}$ and PBS groups (A,B - inserts, hippocampus) and the lack of such cells in the EV-treated group (C - insert). The ca1 and ca3 areas of hippocampus are indicated for reference. (D) Quantification of the number of TUNEL+ cells per 20x eye-field (Mean + SEM). Compared to HI and PBS-treated control animals, Intranasal EV treatment significantly reduced ipsilateral TUNEL+ cell death in cortex (Kruskal-Wallis test, $p=0.0305$; Dunn's test EV vs. PBS ${ }^{*} p=0.0320$ ) and external capsule (Kruskal-Wallis test, $p=0.0131$; Dunn's test EV vs. PBS ${ }^{*} p=0.0117$ ). CTX, cerebral iscocortex; PYR, pyriform cortex; HIP, hippocampus; STR, striatum; Thal, thalamus; EC, external capsule. Scale bars: $\mathbf{A}-\mathbf{C}=150 \mu \mathrm{m}$; inserts $=15 \mu \mathrm{m}$.

$p=0.0305)$. Using the Dunn's multiple comparisons test, significant decrease was found in EV-treated compared to the PBS treated control group $(p=0.0320)$.

The mean ipsilateral TUNEL+ cell counts per representative area in the external capsule varied significantly between treatment groups (Kruskal-Wallis test, EV: 2.125; PBS: 4.556; HI: 4.09; $p=0.0131)$. Dunn's multiple comparisons test showed significant decrease in the TUNEL+ cell counts in the EV-treated compared to control PBS-treated group $(p=0.0117)$ (Figure 2).

\section{Intranasal Application of MSC-Derived EVs Decreases HI-Mediated \\ Volume Loss}

Intranasal EV-treatment resulted in significant reduction of tissue loss as assessed through NISSL staining, compared to control treated littermates overall (Kruskal-Wallis test, $p=0.0453)$, as well as in pyriform cortex, thalamus, and external capsule (Figure 3).

The mean ipsilateral volume loss in the pyriform cortex varied significantly between treatment groups (Kruskal-Wallis test, EV: 16.13\%; PBS: 25.5\%; HI: 19.63\%; $p=0.0273$ ). Dunn's multiple comparisons test showed significant decrease in the EV-treated compared to the PBS-treated groups $(p=0.0219)$. The mean ipsilateral volume loss in the thalamus varied significantly between treatment groups (Kruskal-Wallis test, EV: 17.53\%; PBS: 23.43\%; HI: 30.44\%; $p=0.0445)$. Dunn's multiple comparisons test showed significant reduction in the EV-treated compared to HI groups $(p=0.0348)$. The mean ipsilateral volume loss in the external capsule varied significantly between treatment groups (Kruskal-Wallis test, EV: 10.8\%; PBS: 25.21\%; HI: 21.63\%; $p=0.0114)$. Dunn's multiple comparisons test showed significant decrease in the EV-treated compared to the PBS-treated control groups $(p=0.0126)$ (Figure 3 ).

\section{Intranasal Application of MSC-Derived EVs Improves Behavioral Outcomes}

Intranasal administration of MSC-derived EVs significantly improved behavioral outcomes using the negative geotaxis test at $48 \mathrm{~h}$ (postnatal day 11, P11) postneonatal HI insult compared to control-treated animals (Figure 4). The KruskalWallis test showed significant variation in the mean-time in seconds between treatment groups $(p=0.0151)$. Dunn's 

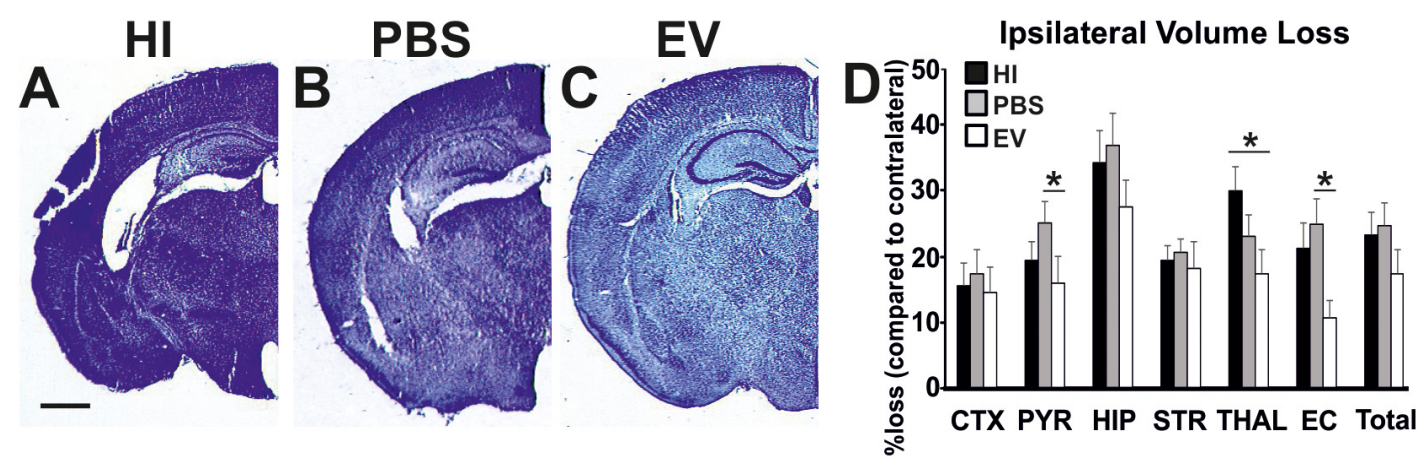

FIGURE 3 | Intranasal application of MSC-derived EVs, immediately following HI, significantly reduces tissue loss after 48 h. Ipsilateral forebrain Nissl staining (Cresyl-Violet, at rostral parietal level) of HI (A), PBS- (B), and EV-treated (C) animals and quantification of ipsilateral brain tissue volume loss (D) at $48 \mathrm{~h}$ following $\mathrm{HI}$-insult. Intranasal EV treatment reduced volume loss (Mean + SEM) compared to HI and PBS-treated littermates (Kruskal-Wallis test, $p=0.0453$ ) with significant, individual decrease in pyriform cortex (Kruskal-Wallis test, $p=0.0273$; Dunn's test EV vs. PBS * $p=0.0219$ ), thalamus (Kruskal-Wallis test, $p=0.0445$; Dunn's test EV vs. HI * $p=0.0348$ ), and external capsule (Kruskal-Wallis test, $p=0.0114$; Dunn's test EV vs. PBS * $p=0.0126$ ). CTX, cerebral iscocortex; PYR, pyriform cortex; HIP, hippocampus; STR, striatum; Thal, thalamus; EC, external capsule. Scale bars: $\mathbf{A}-\mathbf{C}=470 \mu \mathrm{m}$.

multiple comparisons test showed significant decrease of the time necessary for change of orientation in the EV-treated compared to the HI-alone group ( $p=0.0114$ ) (Figure 4).

\section{DISCUSSION}

Our study shows evidence for neuroprotective effects of MSCderived EVs via intranasal administration following neonatal $\mathrm{HI}$ brain injury, using the Rice-Vannucci mouse model in P9 mice. Intranasal treatment with MSC-derived EVs, immediately after severe ( $1 \mathrm{~h}$ ) hypoxia following unilateral carotid artery occlusion, significantly reduced microglial activation, cell death, and tissue loss in the various brain regions tested, compared to brains in control-treated or untreated groups. In addition, compared to control littermates, intranasal EV treatment significantly

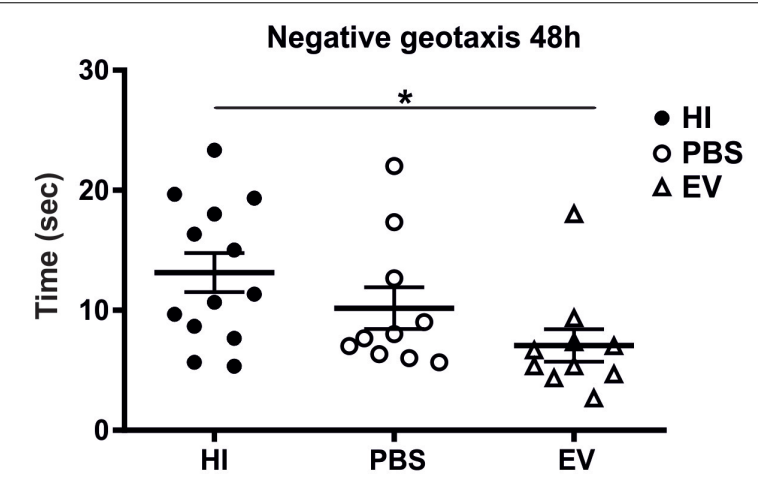

FIGURE 4 | Intranasal application of MSC-derived EVs, immediately following $\mathrm{HI}$ reduces the time required to change orientation in negative geotaxis following neonatal $\mathrm{HI}$ at $48 \mathrm{~h}$ (postnatal day 11). Intranasal treatment with MSC-derived EVs immediately following $\mathrm{HI}$ significantly reduces the time necessary for change of orientation compared to $\mathrm{HI}$ and PBS-treated littermate controls (Kruskal-Wallis test, $p=0.0151$, Dunn's test EV vs. HI $\left.{ }^{*} p=0.0114\right)$. improved short term behavioral outcomes as assessed through negative geotaxis.

Microglial activation was significantly reduced in cortex, hippocampus and striatum, while reduction in cell death was found in cortex and external capsule in the EV-treated group. Tissue volume loss was significantly reduced in pyriform cortex, thalamus and external capsule in the EV-treated group. Assessing all brain regions, the total brain regional means were also significantly decreased for microglial activation and tissue volume loss in the EV-treated groups.

These results are in line with findings from previous studies, showing differential vulnerability of certain brain regions to injury (Rocha-Ferreira and Hristova, 2016). HI injury at term, as modeled in this study, tends to damage the entire brain, most notably gray matter in cortex, hippocampus, and/or thalamus (Alexander et al., 2014).

Damage to the cortex, as well as to the thalamus and striatum (Lubics et al., 2005) have been associated with sensorimotor deficits in animal models of HI (Mercuri and Barnett, 2003; Mercuri et al., 2004; Martinez-Biarge et al., 2011). HI damage in the hippocampus and associated projections to the cortex have been shown to result in disrupted memory function and spatial processing (Aylward, 2005). Significant reductions in hippocampus volume have been shown to reduce long-term reference memory, short-term working memory (Ikeda et al., 2001) and impact the necessary role of the hippocampus in spatial navigation and recollection (Packard and McGaugh, 1996; White and McDonald, 2002). The dorsal striatum, namely the nucleus accumbens, may impact non-spatial navigation, and learning (Packard and Knowlton, 2002; White and McDonald, 2002), thus damage to this structure may account for the non-spatial memory deficits seen for example in HI injured rats (Alexander et al., 2014). Fronto-striato-thalamic circuitry damage from HI injury may lead to deficits in attention, executive function, and activity modulation (Aylward, 2005). As studies have shown anxiety-like behavior in mice following HI injury (Sanches et al., 2013), it has been hypothesized that HI injury may be associated 
with susceptibility to other pathologies such as attention-deficit hyperactivity disorder (ADHD), autism and schizophrenia, as the hippocampus and striatum are associated with related cognitive functions (DeLong, 1992; Lou, 1996; Dilenge et al., 2001; Van Petten, 2004; de Haan et al., 2006).

The results of the present study, emphasize the clinical potential of MSC-derived EVs for neuroprotection following neonatal HI injury and are in line with studies using MSC treatment in neonatal HI murine models (van Velthoven et al., 2010, 2012; Kim et al., 2012; Donega et al., 2014) as well as MSC-derived EVs treatment in an ovine neonatal HI model (Ophelders et al., 2016). The use of EVs as therapeutic vesicles is thus of great clinical interest. Previous HI studies using whole MSCs have found neuroprotective potential for these stem cells (van Velthoven et al., 2010; Donega et al., 2014; Park et al., 2015; Ahn et al., 2016; Corcelli et al., 2018) and the therapeutic time window was shown to be extended when combining MSC treatment with hypothermia (Ahn et al., 2018).

As there may be practical drawbacks of using whole MSCs in clinic, the use of MSC-derived EVs has been gaining increased interest. Neuroprotective effects were for example shown in a recent HI study following intravenous administration of MSCderived EVs in an ovine model of transient umbilical cord occlusion in utero, with improved brain function and reduction of the number and duration of seizures following treatment (Ophelders et al., 2016). It has been shown that intravenous MSC delivery to the brain is hampered by the blood brain barrier (BBB) and results in a tendency of the MSCs to accumulate in other organs, such as the lungs (Lappalainen et al., 2008; Fischer et al., 2009). Intra-arterial administration can deliver high numbers of MSCs to the brain (Lappalainen et al., 2008; Li et al., 2010; Pendharkar et al., 2010), however, this method also has high incidences of mortality and impaired cerebral blood flow in rat HI models (Walczak et al., 2008; Pendharkar et al., 2010). Attempts to increase cell delivery by disrupting the $\mathrm{BBB}$ can leave the animal susceptible to infection or toxins (Burgess et al., 2011). Intranasal administration has shown to be superior to intravenous administration in experimental $\mathrm{HI}$ models due to direct transport to the CNS through intranasal drug delivery (Merkus and van den Berg, 2007) via the olfactory and trigeminal neural pathways, which innervate the nasal cavity and create a direct pathway to the CNS (Hanson and Frey, 2008). Thus in this study we delivered MSC-derived EVs intranasally, as this method is more efficient and far less invasive than intracranial, intravenous or intraarterial deliveries and avoids inactivation by the gastrointestinal and hepatic firstpass metabolism (Hanson et al., 2013; Djupesland et al., 2014; Kozlovskaya et al., 2014). The MSC-derived EVs used in this study are well characterized (Collino et al., 2015; Bruno et al., 2017; GEO GSE59958; Supplementary Figure S1) and have previously shown to regenerative potential in murine acute renal injury models (Bruno et al., 2012; Bruno et al., 2017).

In the current study, we assessed the neuroprotective effects of MSC-derived EVs following intranasal administration after a HI-insult. We observed significant neuroprotective effects and improved short-term behavioral outcomes. This bodes well for future applications of MSC-derived EVs, or EVs derived from other stem cells, following neonatal $\mathrm{HI}$ and may also be translatable to other types of neurotrauma. Tracing of MSCderived EVs, using PKH26 (Long et al., 2017), would further provide information on the exact fate of intranasally delivered $\mathrm{EVs}$ to specific brain-regions and such tracing of EV fate is indeed planned by our group, alongside assessment on longerterm outcomes following MSC-EV treatment. The application of stem-cell derived EVs in combination with hypothermia, for an extended therapeutic time window, should also be explored. The preparation of the EVs is relatively inexpensive and simple, but for successful translation into the clinic strict quality control of MSC cultures and well characterized MSC-derived EVs will be required. Overall our data suggests that intranasal application of MSC-derived EVs following neonatal HI insult has neuroprotective effects and thus possesses potential as clinical treatment for neonatal HI brain damage.

\section{DATA AVAILABILITY}

All data generated or analyzed during this study are included in this published article.

\section{AUTHOR CONTRIBUTIONS}

CS and MH carried out the animal experiments. SK, MHS, SB, $\mathrm{MD}, \mathrm{GC}$, and JI prepared and characterized the MSC-EVs. CS, $\mathrm{JN}$, and $\mathrm{MH}$ generated the histological and behavioral data. All authors contributed to data analysis and read and approved the final manuscript. SL and $\mathrm{MH}$ co-designed the study and wrote the manuscript.

\section{FUNDING}

This work was supported in parts by the BBSRC LIDo, UCLB Apolo PoC, the UCL graduate school and a University of Westminster Start-Up Grant. The funding bodies had no role in the design of the study, analysis, interpretation of data, or writing the manuscript.

\section{SUPPLEMENTARY MATERIAL}

The Supplementary Material for this article can be found online at: https://www.frontiersin.org/articles/10.3389/fphys. 2019.00282/full\#supplementary-material

FIGURE S1 | Characterization of the MSC-derived EVs used in the current study for intranasal application following HI. (A) Nanosight analysis showing EVs in the size range of 30-1000 nm. (B) Electron microscopy showing purified MSC-derived EVs, the scale bar represents $0.5 \mu \mathrm{m}$. (C) FACS analysis verifying the presence of the following MSC-EV specific markers: CD105, CD44, CD73, CD29, CD63, and CD81. (D) Western blotting showing MSC-EV specific markers CD63 and CD9. 


\section{REFERENCES}

Ahn, S. Y., Chang, Y. S., and Park, W. S. (2016). Stem cells for neonatal brain disorders. Neonatology 109, 377-383. doi: 10.1159/000444905

Ahn, S. Y., Chang, Y. S., Sung, D. K., Sung, S. I., and Park, W. S. (2018). Hypothermia broadens the therapeutic time window of mesenchymal stem cell transplantation for severe neonatal hypoxic ischemic encephalopathy. Sci. Rep. 8:7665. doi: $10.1038 / \mathrm{s} 41598-018-25902-\mathrm{x}$

Alexander, M., Garbus, H., Smith, A. L., Rosenkrantz, T. S., and Fitch, R. H. (2014). Behavioral and histological outcomes following neonatal HI injury in a preterm (P3) and term (P7) rodent model. Behav. Brain Res. 259, 85-96. doi: 10.1016/j.bbr.2013.10.038

Aylward, G. P. (2005). Neurodevelopmental outcomes of infants born prematurely. J. Dev. Behav. Pediatr. 26, 427-440. doi: 10.1097/00004703-200512000-00008

Azzopardi, D., Strohm, B., Marlow, N., Brocklehurst, P., Deierl, A., Eddama, O., et al. (2014). Effects of hypothermia for perinatal asphyxia on childhood outcomes. N. Engl. J. Med. 371, 140-149. doi: 10.1056/NEJMoa1315788

Barkovich, A. J., Hajnal, B. L., Vigneron, D., Sola, A., Partridge, J. C., Allen, F., et al. (1998). Prediction of neuromotor outcome in perinatal asphyxia: evaluation of MR scoring systems. AJNR Am. J. Neuroradiol. 19, 143-149.

Bruno, S., Grange, C., Collino, F., Deregibus, M. C., Cantaluppi, V., Biancone, L., et al. (2012). Microvesicles derived from mesenchymal stem cells enhance survival in a lethal model of acute kidney injury. PLoS One 7:e33115. doi: 10.1371/journal.pone.0033115

Bruno, S., Grange, C., Deregibus, M. C., Calogero, R. A., Saviozzi, S., Collino, F., et al. (2009). Mesenchymal stem cell-derived microvesicles protect against acute tubular injury. J. Am. Soc. Nephrol. 20:1053. doi: 10.1681/ASN.2008070798

Bruno, S., Tapparo, M., Collino, F., Chiabotto, G., Deregibus, M. C., Soares Lindoso, R., et al. (2017). Renal regenerative potential of different extracellular vesicle populations derived from bone marrow mesenchymal stromal cells. Tissue Eng. Part A 23, 1262-1273. doi: 10.1089/ten.TEA.2017.0069

Burgess, A., Ayala-Grosso, C. A., Ganguly, M., Jordão, J. F., Aubert, I., and Hynynen, K. (2011). Targeted delivery of neural stem cells to the brain using MRI-guided focused ultrasound to disrupt the blood-brain barrier. PLoS One 6:e27877. doi: 10.1371/journal.pone.0027877

Camussi, G., Deregibus, M. C., and Tetta, C. (2010). Paracrine/endocrine mechanism of stem cells on kidney repair: role of microvesicle-mediated transfer of genetic information. Curr. Opin. Nephrol. Hypertens. 19, 7-12. doi: 10.1097/MNH.0b013e328332fb6f

Castillo, M. (2007). Selective vulnerability and the cerebellum in neonates. AJNR Am. J. Neuroradiol. 28, 20-21.

Clarkson, J., and Herbison, A. E. (2016). Hypothalamic control of the male neonatal testosterone surge. Philos. Trans. R. Soc. London B Biol. Sci. 371:20150115. doi: 10.1098/rstb.2015.0115

Collino, F., Bruno, S., Incarnato, D., Dettori, D., Neri, F., Provero, P., et al. (2015). AKI recovery induced by mesenchymal stromal cell-derived extracellular vesicles carrying MicroRNAs. J. Am. Soc. Nephrol. 26, 2349-2360. doi: 10.1681/ ASN.2014070710

Corcelli, M., Hawkins, K., Vlahova, F., Hunjan, A., Dowding, K., De Coppi, P., et al. (2018). Neuroprotection of the hypoxic-ischemic mouse brain by human CD117+CD90+CD105+ amniotic fluid stem cells. Sci. Rep. 8:2425. doi: 10. 1038/s41598-018-20710-9

Croitoru-Lamoury, J., Lamoury, F. M. J., Caristo, M., Suzuki, K., Walker, D., Takikawa, O., et al. (2011). Interferon- $\gamma$ regulates the proliferation and differentiation of mesenchymal stem cells via activation of indoleamine 2,3 dioxygenase (IDO). PLoS One 6:e14698. doi: 10.1371/journal.pone.0014698

Culman, J., Zhao, Y., Gohlke, P., and Herdegen, T. (2007). PPAR-gamma: therapeutic target for ischemic stroke. Trends Pharmacol. Sci. 28, 244-249. doi: 10.1016/j.tips.2007.03.004

de Haan, M., Wyatt, J. S., Roth, S., Vargha-Khadem, F., Gadian, D., and Mishkin, M. (2006). Brain and cognitive-behavioural development after asphyxia at term birth. Dev. Sci. 9, 350-358. doi: 10.1111/j.1467-7687.2006.00499.x

de Jong, R., Houtgraaf, J. H., Samiei, S., Boersma, E., and Duckers, H. J. (2014). Intracoronary stem cell infusion after acute myocardial infarction: a metaanalysis and update on clinical trials. Circ. Cardiovasc. Interv. 7, 156-167. doi: 10.1161/CIRCINTERVENTIONS.113.001009
DeLong, G. R. (1992). Autism, amnesia, hippocampus, and learning. Neurosci. Biobehav. Rev. 16, 63-70. doi: 10.1016/S0149-7634(05)80052-1

Deregibus, M. C., Cantaluppi, V., Calogero, R., Lo Iacono, M., Tetta, C., Biancone, L., et al. (2007). Endothelial progenitor cell derived microvesicles activate an angiogenic program in endothelial cells by a horizontal transfer of mRNA. Blood 110, 2440-2448. doi: 10.1182/blood-2007-03-078709

Dilenge, M. E., Majnemer, A., and Shevell, M. I. (2001). Long-term developmental outcome of asphyxiated term neonates. J. Child Neurol. 16, 781-792. doi: 10. $1177 / 08830738010160110201$

Djupesland, P. G., Messina, J. C., and Mahmoud, R. A. (2014). The nasal approach to delivering treatment for brain diseases: an anatomic, physiologic, and delivery technology overview. Ther. Deliv. 5, 709-733. doi: 10.4155/tde.14.41

Donega, V., Nijboer, C. H., van Tilborg, G., Dijkhuizen, R. M., Kavelaars, A., and Heijnen, C. J. (2014). Intranasally administered mesenchymal stem cells promote a regenerative niche for repair of neonatal ischemic brain injury. Exp. Neurol. 261, 53-64. doi: 10.1016/j.expneurol.2014.06.009

Drago, D., Cossetti, C., Iraci, N., Gaude, E., Musco, G., Bachi, A., et al. (2013). The stem cell secretome and its role in brain repair. Biochimie 95, 2271-2285. doi: 10.1016/j.biochi.2013.06.020

English, K. (2013). Mechanisms of mesenchymal stromal cell immunomodulation. Immunol. Cell Biol. 91, 19-26. doi: 10.1038/icb.2012.56

Fischer, U. M., Harting, M. T., Jimenez, F., Monzon-Posadas, W. O., Xue, H., Savitz, S. I., et al. (2009). Pulmonary passage is a major obstacle for intravenous stem cell delivery: the pulmonary first-pass effect. Stem Cells Dev. 18, 683-692. doi: $10.1089 /$ scd.2008.0253

Gatti, S., Bruno, S., Deregibus, M. C., Sordi, A., Cantaluppi, V., Tetta, C., et al. (2011). Microvesicles derived from human adult mesenchymal stem cells protect against ischaemia-reperfusion-induced acute and chronic kidney injury. Nephrol. Dial Transplant. 26:1474. doi: 10.1093/ndt/gfr015

György, B., Hung, M. E., Breakefield, X. O., and Leonard, J. N. (2015). Therapeutic applications of extracellular vesicles: clinical promise and open questions. Annu. Rev. Pharmacol. Toxicol. 55, 439-464. doi: 10.1146/annurev-pharmtox010814-124630

Hack, M., Breslau, N., Aram, D., Weissman, B., Klein, N., and Borawski-Clark, E. (1992). The effect of very low birth weight and social risk on neurocognitive abilities at school age. J. Dev. Behav. Pediatr. 13, 412-420. doi: 10.1097/ 00004703-199212000-00005

Hagberg, H., Peebles, D., and Mallard, C. (2002). Models of white matter injury: comparison of infectious, hypoxic-ischaemic, and excitotoxic insults. Ment. Retard. Dev. Disabil. Res. Rev. 8, 30-38. doi: 10.1002/mrdd.10007

Hanson, L. R., Fine, J. M., Svitak, A. L., and Faltesek, K. A. (2013). Intranasal administration of CNS therapeutics to awake mice. J. Vis. Exp. 74:4440. doi: $10.3791 / 4440$

Hanson, L. R., and Frey, W. H. (2008). Intranasal delivery bypasses the bloodbrain barrier to target therapeutic agents to the central nervous system and treat neurodegenerative disease. BMC Neurosci. 9(Suppl. 3):S5. doi: 10.1186/14712202-9-S3-S5

Heldring, N., Mager, I., Wood, M. J. A., and Le Blanc, K. (2015). Therapeutic potential of multipotent mesenchymal stromal cells and their extracellular vesicles. Hum. Gene Ther. 26:506. doi: 10.1089/hum.2015.072

Hristova, M., Cuthill, D., Zbarsky, V., Acosta-Saltos, A., Wallace, A., Blight, K., et al. (2010). Activation and deactivation of periventricular white matter phagocytes during postnatal mouse development. Glia 58, 11-28. doi: 10.1002/ glia.20896

Hristova, M., Rocha-Ferreira, E., Fontana, X., Thei, L., Buckle, R., Christou, M., et al. (2016). Inhibition of Signal Transducer and Activator of Transcription 3 (STAT3) reduces neonatal hypoxic-ischaemic brain damage. J. Neurochem. 136, 981-994. doi: 10.1111/jnc.13490

Ikeda, T., Mishima, K., Yoshikawa, T., Iwasaki, K., Fujiwara, M., Xia, Y. X., et al. (2001). Selective and long-term learning impairment following neonatal hypoxic-ischemic brain insult in rats. Behav. Brain Res. 118, 17-25. doi: 10.1016/ S0166-4328(00)00287-4

Inal, J. M., Ansa-Addo, E. A., Stratton, D., Kholia, S., Antwi-Baffour, S. S., Jorfi, S., et al. (2012). Microvesicles in health and disease. Arch. Immunol. Ther. Exp. 60, 107-121. doi: 10.1007/s00005-012-0165-2

Jacobs, S. E., Berg, M., Hunt, R., Tarnow-Mordi, W. O., Inder, T. E., and Davis, P. G. (2013). Cooling for newborns with hypoxic ischaemic encephalopathy. 
Cochrane Database Syst. Rev. 1: CD003311. doi: 10.1002/14651858.CD0 03311.pub3

Johnston, M. V., Nakajima, W., and Hagberg, H. (2002). Mechanisms of hypoxic neurodegeneration in the developing brain. Neuroscientist 8, 212-220. doi: $10.1177 / 1073858402008003007$

Johnston, M. V., Trescher, W. H., Ishida, A., and Nakajima, W. (2001). Neurobiology of hypoxicischemic injury in the developing brain. Pediatr. Res. 49, 735-741. doi: 10.1203/00006450-200106000-00003

Kang, J. W., Koo, H. C., Hwang, S. Y., Kang, S. K., Ra, J. C., Lee, M. H., et al. (2012). Immunomodulatory effects of human amniotic membrane-derived mesenchymal stem cells. J. Vet. Sci. 13, 23-31. doi: 10.4142/jvs.2012.13.1.23

Kendall, G. S., Hristova, M., Horn, S., Dafou, D., Acosta-Saltos, A., Almolda, B., et al. (2011a). TNF gene cluster deletion abolishes lipopolysaccharide-mediated sensitization of the neonatal brain to hypoxic ischemic insult. Lab. Invest. 91, 328-341. doi: 10.1038/labinvest.2010.192

Kendall, G. S., Hristova, M., Zbarsky, V., Clements, A., Peebles, D. M., Robertson, N. J., et al. (2011b). Distribution of $\mathrm{pH}$ changes in mouse neonatal hypoxicischaemic insult. Dev. Neurosci. 33, 505-518. doi: 10.1159/000333850

Kendall, G. S., Robertson, N. J., Iwata, O., Peebles, D., and Raivich, G. (2006). $\mathrm{N}$-methylisobutyl-amiloride ameliorates brain injury when commenced before hypoxia ischemia in neonatal mice. Pediatr. Res. 59, 227-231. doi: 10.1203/01. pdr.0000196805.68082.22

Kholia, S., Ranghino, A., Garnieri, P., Lopatina, T., Deregibus, M. C., Rispoli, P., et al. (2016). Extracellular vesicles as new players in angiogenesis. Vascul. Pharmacol. 86, 64-70. doi: 10.1016/j.vph.2016.03.005

Kim, E. S., Ahn, S. Y., Im, G. H., Sung, D. K., Park, Y. R., Choi, S. H., et al. (2012). Human umbilical cord blood-derived mesenchymal stem cell transplantation attenuates severe brain injury by permanent middle cerebral artery occlusion in newborn rats. Pediatr. Res. 72, 277-284. doi: 10.1038/pr.2012.71

Kozlovskaya, L., Abou-Kaoud, M., and Stepensky, D. (2014). Quantitative analysis of drug delivery to the brain via nasal route. J. Control Release 189, 133-140. doi: 10.1016/j.jconrel.2014.06.053

Kumral, A., Tuzun, F., Tugyan, K., Ozbal, S., Yllmaz, O., Yesilirmak, C. D., et al. (2012). Role of epigenetic regulatory mechanisms in neonatal hypoxic-ischemic brain injury. Early Hum. Dev. 89, 165-173. doi: 10.1016/j.earlhumdev.2012.09.016

Kurinczuk, J. J., White-Koning, M., and Badawi, N. (2010). Epidemiology of neonatal encephalopathy and hypoxic-ischaemic encephalopathy. Early Hum. Dev. 86, 329-338. doi: 10.1016/j.earlhumdev.2010.05.010

Lamichhane, T. N., Sokic, S., Schardt, J. S., Raiker, R. S., Lin, J. W., and Jay, S. M. (2015). Emerging roles for extracellular vesicles in tissue engineering and regenerative medicine. Tissue Eng. Part B Rev. 21, 45-54. doi: 10.1089/ten.TEB. 2014.0300

Lange, S., Rocha-Ferreira, E., Thei, L., Mawjee, P., Bennett, K., Thompson, P. R., et al. (2014). Peptidylarginine deiminases: novel drug targets for prevention of neuronal damage following hypoxic ischemic insult (HI) in neonates. J. Neurochem. 130, 555-562. doi: 10.1111/jnc. 12744

Lappalainen, R. S., Narkilahti, S., Huhtala, T., Liimatainen, T., Suuronen, T., Närvänen, A., et al. (2008). The SPECT imaging shows the accumulation of neural progenitor cells into internal organs after systemic administration in middle cerebral artery occlusion rats. Neurosci. Lett. 440, 246-250. doi: 10.1016/ j.neulet.2008.05.090

Lee, A. C. C., Kozuki, N., Blencowe, H., Vos, T., Bahalim, A., Darmstadt, G. L., et al. (2013). Intrapartum-related neonatal encephalopathy incidence and impairment at regional and global levels for 2010 with trends from 1990. Pediatr. Res. 74(Suppl. 1), 50-72. doi: 10.1038/pr.2013.206

Lee, C., Mitsialis, S. A., Aslam, M., Vitali, S. H., Vergadi, E., Konstantinou, G., et al. (2012). Exosomes mediate the cytoprotective action of mesenchymal stromal cells on hypoxia-induced pulmonary hypertension. Circulation 126:2601. doi: 10.1161/CIRCULATIONAHA.112.114173

Leisman, G., Braun-Benjamin, O., and Melillo, R. (2014). Cognitive-motor interactions of the basal ganglia in development. Front. Syst. Neurosci. 8:16. doi: 10.3389/fnsys.2014.00016

Li, L., Jiang, Q., Ding, G., Zhang, L., Zhang, Z. G., Li, Q., et al. (2010). Effects of administration route on migration and distribution of neural progenitor cells transplanted into rats with focal cerebral ischemia, an MRI study. J. Cereb. Blood Flow Metab. 30, 653-662. doi: 10.1038/jcbfm.2009.238
Lin, W., Oh, S. K. W., Choo, A. B. H., and George, A. J. T. (2012). Activated T cells modulate immunosuppression by embryonic-and bone marrow-derived mesenchymal stromal cells through a feedback mechanism. Cytotherapy 14, 274-284. doi: 10.3109/14653249.2011.635853

Lloyd, M., Wolfensohn, S., and Thornton, P. (2000). "Quantitative assessment of welfare in experimental animals: the development and use of scoring systems," in Proceedings of the 3rd World Congress on Alternatives and Animal Use in the Life Science: Progress in the Reduction, Refinement and Replacement of Animal Experimentation, eds M. Balls, A.-M. van Zeller, and M. E. Halder (Amsterdam: Elsevier Science), 1107-1117.

Long, Q., Upadhya, D., Hattiangady, B., Kim, D. K., An, S. Y., Shuai, B., et al. (2017). Intranasal MSC-derived A1-exosomes ease inflammation, and prevent abnormal neurogenesis and memory dysfunction after status epilepticus. Proc. Natl. Acad. Sci. U.S.A. 114, E3536-E3545. doi: 10.1073/pnas.1703920114

Lou, H. C. (1996). Etiology and pathogenesis of attention-deficit hyperactivity disorder (ADHD): significance of prematurity and perinatal hypoxic-haemodynamic encephalopathy. Acta Paediatr. 85, 1266-1271. doi: 10.1111/j.1651-2227.1996.tb13909.x

Lubics, A., Reglodi, D., Tamás, A., Kiss, P., Szalai, M., Szalontay, L., et al. (2005). Neurological reflexes and early motor behavior in rats subjected to neonatal hypoxic-ischemic injury. Behav. Brain Res. 157, 157-165. doi: 10.1016/j.bbr. 2004.06.019

Madrigal, M., Rao, K. S., and Riordan, N. H. (2014). A review of therapeutic effects of mesenchymal stem cell secretions and induction of secretory modification by different culture methods. J. Transl. Med. 12:260. doi: 10.1186/s12967-014$0260-8$

Mallard, C., and Vexler, Z. S. (2015). Modeling ischemia in the immature brain: how translational are animal models? Stroke 46, 3006-3011. doi: 10.1161/ STROKEAHA.115.007776

Mallard, C., Welin, A. K., Peebles, D., Hagberg, H., and Kjellmer, I. (2003). White matter injury following systemic endotoxemia or asphyxia in the fetal sheep. Neurochem. Res. 28, 215-223. doi: 10.1023/A:1022368915400

Martin, L. J., Brambrink, A., Koehler, R. C., and Traystman, R. J. (1997). Primary sensory and forebrain motor systems in the newborn brain are preferentially damaged by hypoxia-ischemia. J. Comp. Neurol. 377, 262-285. doi: 10.1002/ (SICI) 1096-9861(19970113)377:2<262::AID-CNE8>3.0.CO;2-1

Martinez-Biarge, M., Diez-Sebastian, J., Kapellou, O., Gindner, D., Allsop, J. M., Rutherford, M. A., et al. (2011). Predicting motor outcome and death in term hypoxic-ischemic encephalopathy. Neurology 76, 2055-2061. doi: 10.1212/ WNL.0b013e31821f442d

McQuillen, P. S., Sheldon, R. A., Shatz, C. J., and Ferriero, D. M. (2003). Selective vulnerability of subplate neurons after early neonatal hypoxiaischemia. J. Neurosci. 23, 3308-3315. doi: 10.1523/JNEUROSCI.23-08-03308. 2003

Meisel, R., Zibert, A., Laryea, M., Göbel, U., Däubener, W., and Dilloo, D. (2004). Human bone marrow stromal cells inhibit allogeneic T-cell responses by indoleamine 2,3-dioxygenasemediated tryptophan degradation. Blood 103, 4619-4621. doi: 10.1182/blood-2003-11-3909

Mercuri, E., Barnett, A., Rutherford, M., Guzzetta, A., Haataja, L., Cioni, G., et al. (2004). Neonatal cerebral infarction and neuromotor outcome at school age. Pediatrics 113, 95-100. doi: 10.1542/peds.113.1.95

Mercuri, E., and Barnett, A. L. (2003). Neonatal brain MRI and motor outcome at school age in children with neonatal encephalopathy: a review of personal experience. Neural Plast. 10, 51-57. doi: 10.1155/NP.2003.51

Merino-González, C., Zuñiga, F. A., Escudero, C., Ormazabal, V., Reyes, C., NovaLamperti, E., et al. (2016). Mesenchymal stem cell-derived extracellular vesicles promote angiogenesis: potencial clinical application. Front. Physiol. 7:24. doi: 10.3389/fphys.2016.00024

Merkus, F. W. H. M., and van den Berg, M. P. (2007). Can nasal drug delivery bypass the bloodbrain barrier: questioning the direct transport theory. Drugs R. D. 8, 133-144. doi: 10.2165/00126839-200708030-00001

Németh, K., Leelahavanichkul, A., Yuen, P. S. T., Mayer, B., Parmelee, A., Doi, K., et al. (2009). Bone marrow stromal cells attenuate sepsis via prostaglandin E(2)dependent reprogramming of host macrophages to increase their interleukin-10 production. Nat. Med. 15, 42-49. doi: 10.1038/nm.1905

Ophelders, D. R. M. G., Wolfs, T. G. A. M., Jellema, R. K., Zwanenburg, A., Andriessen, P., Delhaas, T., et al. (2016). Mesenchymal stromal cell-derived 
extracellular vesicles protect the fetal brain after hypoxia-ischemia. Stem Cells Transl. Med. 5, 754-763. doi: 10.5966/sctm.2015-0197

Packard, M. G., and Knowlton, B. J. (2002). Learning and memory functions of the Basal Ganglia. Annu. Rev. Neurosci. 25, 563-593. doi: 10.1146/annurev.neuro. 25.112701.142937

Packard, M. G., and McGaugh, J. L. (1996). Inactivation of hippocampus or caudate nucleus with lidocaine differentially affects expression of place and response learning. Neurobiol. Learn. Mem. 65, 65-72. doi: 10.1006/nlme.1996.0007

Park, W. S., Sung, S. I., Ahn, S. Y., Yoo, H. S., Sung, D. K., Im, G. H., et al. (2015). Hypothermia augments neuroprotective activity of mesenchymal stem cells for neonatal hypoxic-ischemic encephalopathy. PLoS One 10:e0120893. doi: 10.1371/journal.pone.0120893

Pendharkar, A. V., Chua, J. Y., Andres, R. H., Wang, N., Gaeta, X., Wang, H., et al. (2010). Biodistribution of neural stem cells after intravascular therapy for hypoxic-ischemia. Stroke 41, 2064-2070. doi: 10.1161/STROKEAHA.109. 575993

Perlman, J. M. (2006). Intervention strategies for neonatal hypoxic-ischemic cerebral injury. Clin. Ther. 28, 1353-1365. doi: 10.1016/j.clinthera.2006.09.005

Pirianov, G., Brywe, K. G., Mallard, C., Edwards, A. D., Flavell, R. A., Hagberg, H., et al. (2007). Deletion of the c-Jun N-terminal kinase 3 gene protects neonatal mice against cerebral hypoxic-ischaemic injury. J. Cereb. Blood Flow Metab. 27, 1022-1032. doi: 10.1038/sj.jcbfm.9600413

Prockop, D. J., and Oh, J. Y. (2012). Mesenchymal stem/stromal cells (MSCs): role as guardians of inflammation. Mol. Ther. 20, 14-20. doi: 10.1038/mt.2011.211

Ranghino, A., Cantaluppi, V., Grange, C., Vitillo, L., Fop, F., Biancone, L., et al. (2012). Endothelial progenitor cell-derived microvesicles improve neovascularization in a murine model of hindlimb ischemia. Int. J. Immunopathol. Pharmacol. 25, 75-85. doi: 10.1177/039463201202500110

Robbins, P. D., and Morelli, A. E. (2014). Regulation of immune responses by extracellular vesicles. Nat. Rev. Immunol. 14, 195-208. doi: 10.1038/nri3622

Rocha-Ferreira, E., and Hristova, M. (2016). Plasticity in the neonatal brain following hypoxic-ischaemic injury. Neural Plast. 2016:4901014. doi: 10.1155/ 2016/4901014

Rocha-Ferreira, E., Phillips, E., Francesch-Domenech, E., Thei, L., Peebles, D. M., Raivich, G., et al. (2015). The role of different strain backgrounds in bacterial endotoxin-mediated sensitization to neonatal hypoxic-ischemic brain damage. Neuroscience 311, 292-307. doi: 10.1016/j.neuroscience.2015.10.035

Rocha-Ferreira, E., Vincent, A., Bright, S., Peebles, D. M., and Hristova, M. (2018). The duration of hypothermia affects short-term neuroprotection in a mouse model of neonatal hypoxic ischaemic injury. PLoS One 13:e0199890. doi: 10. 1371/journal.pone.0199890

Rong, L.-J., Chi, Y., Yang, S.-G., Chen, D.-D., Chen, F., Xu, S.-X., et al. (2012). Effects of interferon- $\gamma$ on biological characteristics and immunomodulatory property of human umbilical cord-derived mesenchymal stem cells. Zhongguo Shi Yan Xue Ye Xue Za Zhi 20, 421-426.

Sanches, E. F., Arteni, N. S., Nicola, F., Boisserand, L., Willborn, S., and Netto, C. A. (2013). Early hypoxia-ischemia causes hemisphere and sex-dependent cognitive impairment and histological damage. Neuroscience 237, 208-215. doi: 10.1016/j.neuroscience.2013.01.066

Schmidt-Kastner, R. (2015). Genomic approach to selective vulnerability of the hippocampus in brain ischemia-hypoxia. Neuroscience 309, 259-279. doi: 10. 1016/j.neuroscience.2015.08.034

Shankaran, S., Pappas, A., McDonald, S. A., Vohr, B. R., Hintz, S. R., Yolton, K., et al. (2012). Childhood outcomes after hypothermia for neonatal encephalopathy. N. Engl. J. Med. 366, 2085-2092. doi: 10.1056/NEJMoa1112066

Tan, C. Y., Lai, R. C., Wong, W., Dan, Y. Y., Lim, S. K., and Ho, H. K. (2014). Mesenchymal stem cell-derived exosomes promote hepatic regeneration in drug-induced liver injury models. Stem Cell Res. Ther. 5:76. doi: 10.1186/scrt465

Thei, L., Rocha-Ferreira, E., Peebles, D., Raivich, G., and Hristova, M. (2018). Extracellular signal-regulated kinase 2 has duality in function between neuronal and astrocyte expression following neonatal hypoxic-ischaemic cerebral injury. J. Physiol. doi: 10.1113/JP275649 [Epub ahead of print].

Tricarico, C., Clancy, J., and D'Souza-Schorey, C. (2017). Biology and biogenesis of shed microvesicles. Small GTPases 8, 220-232. doi: 10.1080/21541248.2016. 1215283

Uccelli, A., Moretta, L., and Pistoia, V. (2008). Mesenchymal stem cells in health and disease. Nat. Rev. Immunol. 8, 726-736. doi: 10.1038/nri2395

Uria-Avellanal, C., and Robertson, N. J. (2014). Na+/H+ exchangers and intracellular $\mathrm{pH}$ in perinatal brain injury. Transl. Stroke Res. 5, 79-98. doi: 10.1007/s12975-013-0322-x
Vallabhaneni, K. C., Penfornis, P., Dhule, S., Guillonneau, F., Adams, K. V., Mo, Y. Y., et al. (2015). Extracellular vesicles from bone marrow mesenchymal stem/stromal cells transport tumor regulatory microRNA, proteins, and metabolites. Oncotarget 6:4953. doi: 10.18632/oncotarget.3211

van Niel, G., D'Angelo, G., and Raposo, G. (2018). Shedding light on the cell biology of extracellular vesicles. Nat. Rev. Mol. Cell Biol. 19, 213-228. doi: $10.1038 /$ nrm.2017.125

Van Petten, C. (2004). Relationship between hippocampal volume and memory ability in healthy individuals across the lifespan: review and meta-analysis. Neuropsychologia 42, 1394-1413. doi: 10.1016/j.neuropsychologia.2004.04.006

van Velthoven, C. T. J., Kavelaars, A., and Heijnen, C. J. (2012). Mesenchymal stem cells as a treatment for neonatal ischemic brain damage. Pediatr. Res. 71, 474-481. doi: 10.1038/pr.2011.64

van Velthoven, C. T. J., Kavelaars, A., van Bel, F., and Heijnen, C. J. (2010). Mesenchymal stem cell treatment after neonatal hypoxic-ischemic brain injury improves behavioral outcome and induces neuronal and oligodendrocyte regeneration. Brain Behav. Immun. 24, 387-393. doi: 10.1016/j.bbi.2009.10.017

Vannucci, R. C., and Vannucci, S. J. (1997). A model of perinatal hypoxic-ischemic brain damage. Ann. N. Y. Acad. Sci. 835, 234-249. doi: 10.1111/j.1749-6632. 1997.tb48634.x

Vohr, B. R., Wright, L. L., Dusick, A. M., Mele, L., Verter, J., Steichen, J. J., et al. (2000). Neurodevelopmental and functional outcomes of extremely low birth weight infants in the National Institute of Child Health and Human Development Neonatal Research Network, 1993-1994. Pediatrics 105, 12161226. doi: $10.1542 /$ peds.105.6.1216

Volpe, J. J. (2001). Perinatal brain injury: from pathogenesis to neuroprotection. Ment. Retard. Dev. Disabil. Res. Rev. 7, 56-64. doi: 10.1002/1098-2779(200102) 7:1<56::AID-MRDD1008>3.0.CO;2-A

Volpe, J. J. (2012). Neonatal encephalopathy: an inadequate term for hypoxicischemic encephalopathy. Ann. Neurol. 72, 156-166. doi: 10.1002/ana.23647

Walczak, P., Zhang, J., Gilad, A. A., Kedziorek, D. A., Ruiz-Cabello, J., Young, R. G., et al. (2008). Dual-modality monitoring of targeted intraarterial delivery of mesenchymal stem cells after transient ischemia. Stroke 39, 1569-1574. doi: 10.1161/STROKEAHA.107.502047

Wen, S., Dooner, M., Cheng, Y., Papa, E., Del Tatto, M., Pereira, M., et al. (2016). Mesenchymal stromal cell-derived extracellular vesicles rescue radiation damage to murine marrow hematopoietic cells. Leukemia 30, 2221-2231. doi: 10.1038/leu.2016.107

White, N. M., and McDonald, R. J. (2002). Multiple parallel memory systems in the brain of the rat. Neurobiol. Learn. Mem. 77, 125-184. doi: 10.1006/nlme.2001. 4008

Wu, Y. W., and Colford, J. M. Jr. (2000). Chorioamnionitis as a risk factor for cerebral palsy: a meta analysis. JAMA 284, 1417-1424. doi: 10.1001/jama.284. 11.1417

Wyatt, J. S., Gluckman, P. D., Liu, P. Y., Azzopardi, D., Ballard, R., Edwards, A. D., et al. (2007). Determinants of outcomes after head cooling for neonatal encephalopathy. Pediatrics 119, 912-921. doi: 10.1542/peds.2006-2839

Yeo, R. W. Y., Lai, R. C., Zhang, B., Tan, S. S., Yin, Y., Teh, B. J., et al. (2013). Mesenchymal stem cell: an efficient mass producer of exosomes for drug delivery. Adv. Drug Deliv. Rev. 65, 336-341. doi: 10.1016/j.addr.2012.07.001

Yi, J. H., Park, S. W., Kapadia, R., and Vemuganti, R. (2007). Role of transcription factors in mediating post-ischemic cerebral inflammation and brain damage. Neurochem. Int. 50, 1014-1027. doi: 10.1016/j.neuint.2007. 04.019

Zhang, S., Chu, W. C., Lai, R. C., Lim, S. K., Hui, J. H. P., and Toh, W. S. (2016). Exosomes derived from human embryonic mesenchymal stem cells promote osteochondral regeneration. Osteoarthr. Cartil. 24, 2135-2140. doi: 10.1016/j. joca.2016.06.022

Conflict of Interest Statement: The authors declare that the research was conducted in the absence of any commercial or financial relationships that could be construed as a potential conflict of interest.

Copyright $\odot 2019$ Sisa, Kholia, Naylor, Herrera Sanchez, Bruno, Deregibus, Camussi, Inal, Lange and Hristova. This is an open-access article distributed under the terms of the Creative Commons Attribution License (CC BY). The use, distribution or reproduction in other forums is permitted, provided the original author(s) and the copyright owner(s) are credited and that the original publication in this journal is cited, in accordance with accepted academic practice. No use, distribution or reproduction is permitted which does not comply with these terms. 